\title{
A Proposed Talent Management Model for Leader-Managers in State-Owned Enterprises in China
}

\author{
LeAnn M. Brown, SPHR, PhD (corresponding author) \\ Dept. of Management and Marketing, Fort Hays State University \\ 600 Park Street, Hays, Kansas 67601
}

Tel: 1-785-628-5343Ｅ-mail: leannbrown@fhsu.edu

Doi:10.5296/ijhrs.v4i3.6011ＵRL: http://dx.doi.org/10.5296/ijhrs.v4i3.6011

\begin{abstract}
Due to the continued reform of state-owned enterprises (SOEs) in China, SOE leaders face many challenges competing in a rapidly changing global marketplace. Not only are leaders tasked to manage change, but they must also deliver results and increase revenue through human capital. The need for stronger human capital and human resources (HR) must play a stronger role in SOEs by adopting new strategies for talent management.

The purpose of this study explores the experiences and perceptions of leader-managers as it relates to talent management in SOEs in China. Upon conducting phenomenological interviews with 11 state-owned companies and 17 leader-manager participants, analysis was completed to determine themes related to leadership-management selection, development, and practices in SOEs in China.

Themes emerged from the data analysis including organizational structure and its influence on leader-manager selection; an overview of the leadership pipeline present in SOEs including the recruitment and selection process and succession planning strategies; HR's role within the recruitment and selection process; leadership-management development through experience and other development strategies; influence of Chinese and Western culture and on talent management and leader-manager practices.

The findings were synthesized to introduce a proposed talent management model for SOEs in China. The proposed model provides HR practitioners a framework to manage talent within their organizations, in particular in the areas of recruiting, developing, and retaining successful leader-managers within SOEs in China.
\end{abstract}

Keywords: China, state-owned enterprises, talent management, human resource management 


\section{Introduction}

Chinese SOEs face many challenges due to the continued reform of SOEs and the rapidly increasing Chinese economy. Leaders of these organizations must lead in a way that respects the traditional canons and practices of traditional China while also embracing contemporary approaches to leadership. SOE leaders are not only tasked with the responsibility to deliver results and increase revenue but also required to manage and invest in the development of their employees. According to Keeley (2004), no other issue is more important to SOEs than developing effective leaders and managers.

While research studies have been completed on leadership-management practices in Chinese organizations, limited research is available on talent management, in particular leadership selection, development, and practices in SOEs in China. Beyond addressing the gap in literature regarding leader-manager talent management (TM), studying the experiences and perceptions of leader-managers in SOEs in China can provide valuable insight for human resources (HR) professionals charged with managing leader-manager TM within SOEs. Only when HR professionals understand the current TM practices of the company, can they develop strategies and interventions to address the leadership challenges in today's Chinese organizations.

\section{Research Questions}

The purpose of this paper explores the perceptions and experiences of SOE leader- managers on TM within their organization. Using the data collected in this study, a grounded theory approach was used to propose a TM model for SOEs in China.

The research questions for this study included the following:

1) How are Chinese SOE leader-managers identified and selected, and what role does HR play in the selection process?

2) What factors and experiences contribute to SOE leader-managers leadership and management development?

3) What are SOE leader-managers' perceptions of leadership and management practices, and what influences and prior experiences shape their current leadership practices?

The terms leader and manager are interchanged in the research associated with leadership development and TM. For this particular study, leader-managers include anyone with direct reports including middle management, general managers, presidents, etc.

\section{Literature Review}

\subsection{Leadership and Management}

Throughout history, scholars and philosophers have studied and introduced various leadership theories and concepts in an effort to describe the traits and behaviors of leadership (Bass, 1990). A number of definitions have been introduced to describe leadership; however, 
depending upon the context and the researcher's bias, these definitions can vary (Northouse, 2010). Some theorists have defined leadership by focusing on traits, behaviors, situations, and or context (Bass, 1990). According to Northouse (2007), "leadership is defined as a process whereby an individual influences a group of individuals to achieve a common goal" (p. 3).

\subsection{Leadership versus Management}

The terms leader and manager are interchanged throughout much of the literature related to research studies of organizational leaders or managers in Western and Chinese organizations. According to Kotterman (2006), leaders are seen as charismatic change agents who inspire and motive others to achieve organizational goals for the common good, and managers are seen as task-oriented individuals who care only about operations, organizational performance and the bottom-line. Yukl (1989) argues that organizational leaders must possess both leadership and management knowledge and abilities in order to be successful in today's complex organizations.

Defining leadership and management has been difficult for scholars and practitioners over the last century as many definitions have been introduced throughout the research (Yukl, 1989). According to Kotter (2001), leadership and management are two distinctive and complementary systems of action. "Each has its own function and characteristic activities. Both are necessary for success in an increasingly complex and volatile business environment" (Kotter, 2001, p. 3).

Due to the nature of this exploratory study, both leadership and management theories and practices are relevant to this research. Thus, the term leader-manager will be used throughout the study to encompass organizational leaders or managers who demonstrate both leadership and/or management behaviors in their roles within the SOE organization.

\subsection{Talent Management}

Although the scope and definition of TM differ among researchers, TM includes the HR/OD functions of identifying, developing, and retaining high potential employees for future leader-manager positions in the organization (Stahl et al., 2012). According to Abduljlil ALDamoe, Yazam, Ahmid (2012), "Employee retention has emerged as one of the major focus in the recent years in HRM studies, particularly as part of talent management programs" (p. 83). Mathis and Jackson (2008) state that TM goes beyond retention and incorporates more elements of the talent management process by including training, career planning, HR development, succession planning, performance management, and qualified workforce supply/demand match; however, the overall strategic objective of TM is to develop and sustain leaders so that organizations can be successful (Mathis \& Jackson, 2008, p. 292).

\subsection{Leadership-Management in China}

Due to the rapid growth of the Chinese economy, research interest in leadership and human resource practices in China has increased (Liang, Marler, \& Cui, 2012). The increased global competition, the rapid growth of the economy, and the arrival of the millennial 
generation in the workplace has generated more interest from scholars and practitioners to study leadership and management practices in China, in particular from the perspective of leader-manager's attitudes, values, and beliefs associated with workplace leadership in the Chinese context (Chao, 2012). The following section describes leadership and management research from a Chinese perspective and/or context.

\subsection{Chinese Leadership Theories and Canons}

The death of Chairman Mao in 1976 transitioned China into the second generation of leaders with eventual power transitioning to Deng Xiaoping ( $\mathrm{Li}, 2001$ ). This generation focused on economic development and led China's economic reform. Chairman Mao and Deng Xiaoping's leadership philosophies continue to impact leadership and management practices today in China.

\subsubsection{Deng Xiaoping's Influence}

Since China's reform in 1979, Deng's theories and works have been a mandatory subject in leadership courses in academic institutions and training programs for Party leaders. The focus of Deng's works include philosophy of leadership, leaders' behavior, China's legal system, the art of leadership, and leadership selection (Vogel, 2011). To know employees completely, leaders must engage employees to understand their morality, knowledge, talent, diligence and hard work, accomplishments, personality, predispositions, age, type, and experience (Vogel, 2011). Followers should support individuals in leadership positions by supporting the Party and serving others. Deng also recommends that leaders should exchange positions periodically to gain business acumen and a stronger understanding of the company (Vogel, 2011). Due to Deng Xiaoping's role in economic reform in China, he is one of the most admired leaders in China.

\subsubsection{Confucius Leadership Theory}

Confucius leadership theory originates from the early teachings of Confucius, an ancient philosopher of China. His teachings were grounded in social, political, religious, and moral philosophies of thought and are deeply rooted in the Chinese culture. Confucius leaders strive for harmonious relationships, respect those in authority or who are elders, and work towards stability and solidarity within the organization (Dhakhwa \& Enriquez, 2008).

\subsubsection{Paternalistic Leadership}

Paternalistic leadership is a native Chinese leadership style also originating from Confucianism. Paternalistic Leadership encompasses three main elements: autocratic leadership, benevolent leadership and moral leadership (Chen \& Lee, 2008). Chang (2005) describes paternalistic leadership as "someone who believes in the policy of controlling other people in a fatherly way by providing them what they need, but giving them little or no responsibility of freedom of choice" (p. 34). He states paternalistic leadership involves "acting for the good of another person without that person's consent-as fathers can do for their children. Paternalism is controversial because, by definition, its end is benevolent, but its means are coercive" (Chang, 2005, p. 34). This type of leadership is evident in Chinese 
organizations and throughout the country largely due to the communist influence within the country.

\subsubsection{Bingjia}

Bingiia is "an extensive and influential canon of texts on the conduct of warfare and associated affairs of state that includes those that were subsequently acquired during the Song dynasty as the Seven Military Classics" (Ford, 2010, p. 53). This canon of texts provided a foundation for strategies related to military affairs and military leadership.

\subsubsection{Daoism or Taoism}

Daoism, or formerly known as Taoism, is deeply rooted in the yin-yang philosophy of China of the interweaving and balance of opposing but complementary forces (Ford, 2010). These ideals centered on humility and a lack of involvement in the leadership process. The leader provides support to the followers in order for them to succeed. According to Daoism philosophies, the leader should not seek fame and glory, but to remain pure to better lead his followers for political order and harmonious relationships (Ford, 2010).

\subsubsection{Legalism or the Fa Chia}

According to Ford (2010), "Legalism was a philosophy first and foremost of power" (pp. 49-50). The premise of legalism is the notion that people are evil and must be restrained by laws in order to live happily in society (Ford, 2010). Legalism in China differs from the Western sense of legalism in that the ruler makes the law, is not subject to the law, but uses the law as a means to gain control and power (Ford, 2010). According to Ford (2010), legalism emphasized "the importance of setting up the ruler as the sole dispenser of rewards and punishments in the state and the exclusive arbiter of a system of general and objective laws enforced by swift, harsh punishment for all transgressors (p. 50).

\subsubsection{Guanxi and Leadership}

Wood, Whiteley, and Zhang (2002) researched the use of guanxi in Chinese organizations including SOEs and foreign-owned companies. Guanxi is defined as personal relationships and connections one has in society. According to Wood, Whitely, and Zhang (2002), "In such an environment, business dealings are likely to rely more on the context of individual relationships than on abstract legal representations based on cultural concepts such as justice and equality" (p. 264). By building relationships with others and engaging in collective or participative leadership, guanxi can be used to lead organizations and facilitate change.

\subsection{Literature Review Summary}

Chinese SOEs face many challenges due to the continued reform of SOEs and the rapidly increasing Chinese economy. Leaders of these organizations must lead in a way that respects the traditional canons and practices of traditional China while also embracing Western and contemporary strategies of leadership. While researchers have increasingly studied leadership practices in Chinese organizations, limited research is available on TM in SOEs in China. 


\section{Methods}

To understand the common experiences of leader-managers in SOEs in China as it relates to TM, phenomenological and ethnographical methods were chosen to conduct this study. The researcher attempted to gain insight of TM and leadership-management practices of leader-managers in SOEs in China by asking perceptions and experiences of leader-manager selection, development, and practices. Each participant had the common and lived experience as a leader-manager in an SOE in China. As a foreigner or outsider conducting this research in China, an ethnographical approach was used as well.

\subsection{Participants and Interviews}

Eleven companies in an Eastern Coastal Province of the People's Republic of China agreed to participate in the interviews using two gatekeepers connected to the Chinese government in that particular province. Gatekeeper 1 served as a translator during the interview, and Gatekeeper 2 scheduled each interview throughout the province. Interviews were conducted in-person with the primary researcher and translator/gatekeeper present throughout the interview. The interviews were held at the company and were 60 to 75 minutes in length.

Table 1 provides the demographics of the participants including gender, age, management level, years of service at their current company, and education level.

Table 1. Participant demographics.

\begin{tabular}{|l|l|l|l|c|l|}
\hline \multicolumn{1}{|c|}{ Name } & Gender & $\underline{\text { Age }}$ & $\underline{\text { Mgt Level }}$ & $\underline{\text { Years of Service }}$ & \multicolumn{1}{|c|}{ Education } \\
\hline Leader-Manager 1 & Male & 47 & Top Mgt & 2 & Bachelor \\
\hline Leader-Manager 2 & Male & 57 & Top Mgt & 35 & Master \\
\hline Leader-Manager 3 & Male & 48 & Top Mgt & 20 & Bachelor \\
\hline Leader-Manager 4 & Male & 52 & Top Mgt & 18 & Bachelor \\
\hline Leader-Manager 5 & Male & 37 & Middle Mgt & 15 & Bachelor \\
\hline Leader-Manager 6 & Male & 39 & Top Mgt & 20 & Bachelor \\
\hline Leader-Manager 7 & Male & 47 & Top Mgt & 11 & Master \\
\hline Leader-Manager 8 & Male & 57 & Top Mgt & 22 & Associate \\
\hline Leader-Manager 9 & Male & 41 & Top Mgt & 20 & Bachelor \\
\hline Leader-Manager 10 & Male & 49 & Top Mgt & 32 & Master \\
\hline Leader-Manager 11 & Female & 57 & Top Mgt & 17 & Master \\
\hline Leader-Manager 12 & Female & 35 & Top Mgt & 12 & Master \\
\hline Leader-Manager 13 & Female & 40 & Middle Mgt & 16 & Master \\
\hline Leader-Manager 14 & Female & 38 & Middle Mgt & 16 & Master \\
\hline Leader-Manager 15 & Male & 43 & Top Mgt & 19 & Master \\
\hline Leader-Manager 16 & Male & 46 & Top Mgt & 5 & Bachelor \\
\hline Leader-Manager 17 & Male & 56 & Middle Mgt & 33 & Associate \\
\hline
\end{tabular}




\subsection{Data Analysis}

Coding software (Nvivo 9.2) was used to code and identify potential themes. After identified themes and sub-themes were acknowledged after several revisions, I presented my findings to Gatekeeper 1 to obtain an emic perspective and validation of the research findings. Gatekeeper 1 agreed with my findings and made no changes or recommendations.

\section{Findings}

Upon conducting phenomenological interviews with 11 SOEs and 17 leader-manager participants, several themes emerged from the data analysis including organizational structure and its influence on leader-manager selection; an overview of the leadership pipeline present in SOEs including the recruitment and selection process and succession planning strategies; human resources' role within the recruitment and selection process; leadership-management development through experience and other development strategies; influence of Chinese and Western culture and the Communist Party on talent management and leader-manager practices. The following table provides an overview of the themes and sub-themes that emerged in the findings to create the proposed talent management model introduced later in this paper. The findings indicate the need for HR to play a stronger role in organizational strategy, in particular as it relates to talent management.

Table 2 - Identified Themes and Related Codes

\begin{tabular}{lcl}
\hline Selection Themes & Development Themes & Practice Themes \\
\hline Organizational Structure & Development Through Experience & Leadership Vs Management \\
Related Codes: & Related Codes: & Related Codes: \\
Government and Party & Cross-Functional/Job Rotation & Descriptions of Leadership \\
Influence & Studying or Living Abroad & Descriptions of Management \\
Board of Directors & Exposure to New Challenges & Leadership Top Management \\
Top Management & Childhood Experiences & Managers - Middle Mgt. \\
Middle Management & & \\
Government Appointments & & \\
\hline Leadership-Management & $\mathbf{3 6 0}$ Feedback and Evaluation & Influence of Chinese/Western \\
Pipeline & & Cultures \\
Related Codes: & Related Codes: & Related Codes: \\
Promoted from Within & Performance Evaluation System & Chinese Culture \& \\
Worked from Bottom Up & Western influence of PES & Ideologies \\
Job Allocation Labor Law & Evaluated by Direct Supervisor & Deng Xiaoping \\
College Recruitment & Evaluated by Subordinates & Government Regulations \\
Guanxi & Performance Expectations & Western Culture \\
Challenges for Women & & Social Responsibility \\
Leadership Pool & & Western Leaders \\
Succession Planning & & Career Development \\
Employee File & & Performance Evaluation \\
Demonstration of Performance & & Chinese/Western Theories \\
\hline
\end{tabular}


Role of Human Resources

$\underline{\text { Related Codes: }}$

Importance of $H R$

Administrative Function

Recruitment Identify Talent

Career Development Training

Performance Evaluations

Compensation and Benefits

Lack of HR Training
Corporate Training and University Leader-Manager Competencies Partnerships

Related Codes:

Learning Culture

Corporate Training

Subject Matter Experts

Technical Training

Western Mgt. Experts

Government Training

University Partnerships

Business Schools

College Experience $\underline{\text { Related Codes: }}$

Work Ethic, Results Oriented

Political \& Relationships

Business Acumen

Collaboration, Teams

Integrity, Character

Vision, Strategic, Goals

Identify Employee Potential

Problem Solving

Adapt to Change

Open-Minded, Learning
Challenges Related to Selection

Related Codes:

Competition for Talent

Employee Retention

Manual/Craft Labor Shortage
Exposure to Execs and Mentors

Related Codes:

Exposure to Top Management

Mentors

Nurturing Younger Employees
Organizational Culture in

SOES

Related Codes:

Government Influence

Generational Differences

Change in SOES

\section{Practical Application: TM Model for State-Owned Enterprises}

Using a grounded theory approach the following model is a representation of the data analysis from this study. The figure represents a proposed TM Model for SOEs in China. 
Figure 1 - Proposed Talent Management for SOEs

2014, Vol. 4, No. 3

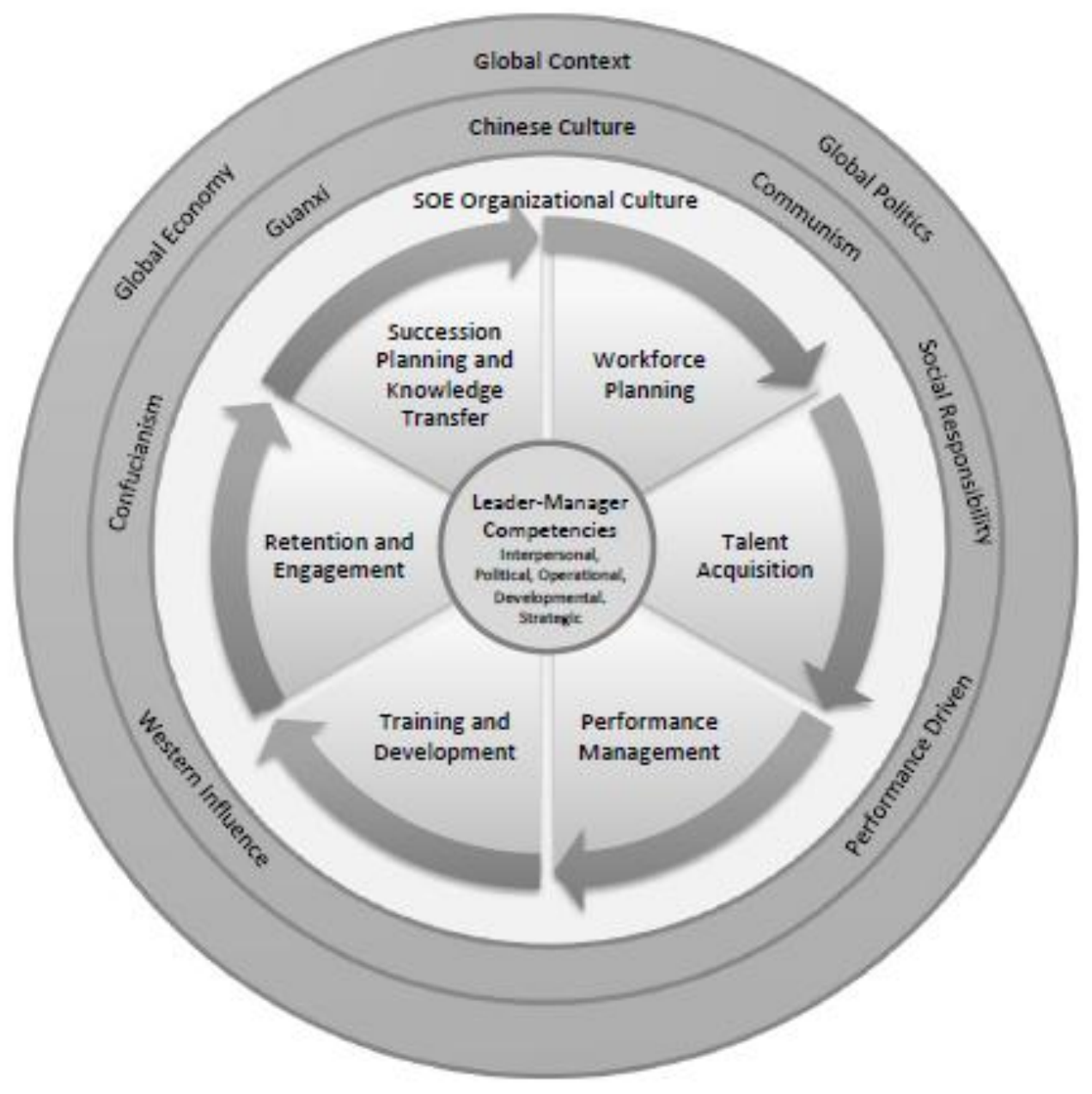

A TM model can guide HR professionals in understanding and identifying TM strategies within the company including workforce planning, talent acquisition, performance management, development, succession planning, and retention. By developing TM strategies within the company, HR practitioners can work to address the talent gaps in today's state-owned companies in China. The following explains each element of the TM Model for SOEs in China.

\subsection{Leadership-Management Competencies}

Leadership-management competencies can be valuable to HR practitioners as it provides a framework and is central for leadership-management TM strategies including selection, development, and practices.

The leadership-management competencies represented in the center of the TM Model for SOEs in China are organized into five competency areas: 1) Interpersonal competencies; 2) Political competencies; 3) Operational competencies; 4) Developmental competencies; and 5) Strategic competencies. The order of the 5 competency areas are aligned with the progression of leader-managers throughout the organization. As an employee continues to navigate the leadership pipeline, he or she will need the additional skill set or next level of 
competencies to be successful in that role. Once employees achieve a top management position, he or she will need to demonstrate all levels of the leadership-management competencies.

The first competency level is termed interpersonal competencies. These competencies focus on the personal and interpersonal abilities of the individual including the demonstration of integrity, the commitment to learning, the ability to manage ambiguity, the demonstration of strong communication skills, the ability to influence others, the ability to build and lead teams, and an attitude of perseverance and drive. All employees within the organization should have these competencies in order to be successful and have the potential to be promoted to a leadership-management role within the company. Employees will also be more successful if they are able to identify the next level of competencies, political competencies.

Political competencies align with the government's influence within the organization. The ability to be politically savvy and resourceful with relationships will increase the leader-manager's opportunity for success. Knowledge of the Party's philosophies and conduct, as well as commitment to the Government, will also provide opportunities for the employee to be more successful. Although these competencies are essential for leader-manager success within SOEs in China, they must be demonstrated in an alignment with integrity and the other personal and interpersonal competencies listed in the above section.

Operational competencies focus more on administrative competencies related to managing and coordinating work. Organizational competencies include organizing and planning, decision making and problem solving, directing others, coordinating and delegating work, and process management. Process management focuses on the ability to create and implement standard work, safety, and total quality management (TQM) programs.

The next element of competencies relates to employee development. Employee development competencies include the ability to identify employee strengths and potential, understanding human capital needs within the organization, ability to provide feedback, and commitment to employee development. By committing to employee development and placing an emphasis on human capital, leader-managers of SOEs can reap long-term success developing future leader-managers for their SOEs.

The last element relates to strategic competencies. Strategic competencies focus on macro level responsibilities within the organization including demonstrating business and industry acumen, creating and implementing vision, strategic agility within the organization, results and goal-oriented, and ability to lead and adapt to change.

\subsection{Workforce Planning}

Although the findings indicated that SOEs value HR within the company, most companies saw HR as a service department to coordinate recruiting, training, and evaluation efforts for individual departments. The recent evolution of HR in China has resulted in an increased focus on human capital; however, many SOEs miss the opportunity to plan and forecast workforce needs within the company. By collaborating with the Board of Directors, top 
management, and middle management teams, HR can provide a workforce plan to address the talent gaps within the SOEs.

\subsection{Talent Acquisition}

Recruiting top talent to SOEs is challenging within the Chinese marketplace. SOEs primarily recruit from universities and through relationships with individuals. By adopting a TM approach, HR practitioners can utilize the proposed leadership-management competencies to evaluate whether potential recruits have the ability to progress through the leadership-management pipeline. The strategy to recruit leader-managers from within is widely accepted throughout SOEs in China; thus, recruiting the right college graduates with the competencies needed for promotion to leader-manager positions is a critical HR strategy that must be adopted in order to be successful in the TM process.

Relying upon guanxi as an identification method has been ineffective within SOEs in China. Many times government officials or employees receive jobs or promotions based upon relationships versus leadership-management competencies and/or industry and business experience. The proposed TM model takes into consideration the government's ideologies and practices that influence SOE's organizational culture and practices, and recommends using the proposed leader-manager competencies to identify potential talent. According to the data analysis, being politically savvy and ethical in combination with leader-manager capabilities can prove to be effective for potential and current leader-managers to navigate the organizational and political complexities within SOEs.

\subsection{Performance Management}

Most SOEs interviewed described their performance evaluation system as thorough and comprehensive; however, the companies vary in their performance indicators for leader-managers. One performance standard consistent throughout the data analysis was the emphasis placed on delivering results and demonstrating high performance. The term "high performance" was not easily defined except by discussing performance related to financial contributions to the company. The proposed TM model recommends utilizing adopted and standardized leadership-management competencies to evaluate the employees and leader-managers in combination with identified performance goals. This combined approach can reward employees who meet performance standards and who also demonstrate the competencies necessary to be effective in a leader-manager role. The competency/performance based evaluation can provide strengths and weaknesses of the leader-manager and provide a baseline for further development of leader-managers.

\subsection{Training and Development}

The commitment to learning emerged as a theme throughout most of the including assessment and evaluation, development through experience, job rotation, corporate training, university partnerships, and exposure to executives and mentors. Adopting a developmental strategy aligned with these current practices could be effective in the development of leader-managers in SOEs in China. 
In addition to development strategies, most companies discussed leadership-management training by focusing on technical aspects of the job versus training as it relates to management or leadership development. An opportunity for further research is to examine the training needs (gap analysis) of SOEs in China and determine the return on investment of training offered in Chinese SOEs. This may also aid in shifting the focus from technical training to interpersonal skills related to leadership-management.

\subsection{Retention and Engagement}

Retention of employees is a challenge as many recruits have difficulty adjusting to the SOE organizational culture. Although rebranding the employment opportunities with SOEs may increase retention, some participants discussed retention strategies such as career development opportunities, focusing on employee satisfaction, and increasing compensation and benefits. The implementation of a formal retention program would be valuable to SOEs in China. By adopting the proposed TM model and leadership-management competencies, SOEs can formulate retention strategies to retain top talent, in particular talent with identified leadership-management potential.

\subsection{Succession Planning and Knowledge Transfer}

Due to the mandatory retirement age for Chinese citizens, companies have the opportunity to prepare for leader-manager retirement by identifying and selecting potential leader-managers from the leadership-management pool. Two companies discussed their strategy of succession planning and transferring knowledge prior to leader-managers retirement; however, this strategy appeared to be rare in the data analysis. Adopting a comprehensive succession plan can allow potential leader-managers to work alongside the leader-manager prior to his/her retirement. This would provide an opportunity for knowledge transfer and allow the new leader-manager to serve in a leadership-management role with support of the retired employee.

\subsection{SOE Organizational Culture}

The role of organizational culture is a common theme throughout the literature and the data analysis. The findings indicated that generational differences and the government's restrictions and influence on SOE culture makes it difficult for SOEs to change rapidly. All aspects of the TM process are influenced by the organizational culture present in SOEs. Leader-managers must be able to navigate and operate in a culture different than MNCs or privately-owned companies within China.

\subsection{Chinese Culture}

The organizational culture is heavily influenced by government ideologies and practices., and the role of the Communist party strongly influences leader-manager practices in SOEs. The commitment to China was verbally stated throughout the interviews including their respect for leaders such as Deng Xiaoping. Many participants' perceptions and experiences related to leadership-management practices aligns with Deng Xiaoping Leadership Theory such as supporting individuals in leadership positions by promoting the Party and serving others. 
This development strategy of job rotation or cross-functional training aligns with many of the companies' development program for potential leaders-managers. This commitment to the Party aligns with the themes related to selection including the influence of the Party on organizational structure, culture, and the leadership-management pipeline. Confucianism also emerged as a theme influencing organizational practices including harmony, respect for authority, stability, and solidarity within the organization.

The use of guanxi highly influences business and employment decisions including the promotion of leader-managers within the SOE. In addition to guanxi, the ideology of social responsibility or obligation to the society aligns with the Paternalistic and Confucius ideologies of the Chinese culture. The participants claimed that if the SOE financially prospers, the employees and thus society would prosper.

Although the Chinese culture plays a significant role influencing leadership-management practices, the Western culture also influences organizational practices in SOEs in China. Participants also discussed learning various leadership-management practices from the Western culture including career and professional development, performance evaluation systems, occupational health standards, and training employees on soft skills in addition to technical skills. The commitment to work ethic and emphasis on performance are also strong influences from both the Chinese and Western cultures.

\subsection{Global Context}

The pressures of the global context, primarily the global economy and political arena, have influenced Chinese SOEs as it relates to business practices and TM practices. Many of the participating companies discussed their concerns regarding the decline in the global economy and the increased competition in the marketplace. Decreasing profits force the SOEs to make changes to respond to the marketplace including technology advances, innovation of services and products, and entering additional markets. Political pressures from other countries, including the US, are forcing SOEs to make changes such as upgrading environmental and safety standards. The complexity and rapid change of the global context are forcing SOEs to make changes in most facets of the business including human capital and TM.

\section{Limitations of Study and Proposed Model}

This researcher interviewed 17 leader-managers actively serving in leadership and/or management roles in eleven SOEs in China. The leader-managers were selected based upon a mutual colleague, Gatekeeper 2. The number of participants is reflective of the suggested number of participants for a qualitative study (Creswell, 2008); however it is only a small representation of leader-managers in SOEs in China. A larger sample size may result in additional or different findings. The results are limited to a single geographic location and limited to the leader-managers who agreed to participate in the semi-structured interviews.

The proposed TM model was created using a grounded theory method from the data analysis. The proposed model creates a need for further theoretical and empirical research on TM strategies and practices in SOEs in China by focusing on the areas of workforce planning, 


\section{Macrothink Institute ${ }^{T M}$}

talent acquisition, retention and engagement, training and development, and succession planning. Additional development of leader-manager competencies associated with specific levels within the organization would be valuable to HR practitioners and scholars interested in the leadership pipeline and developing potential leader-managers with SOEs in China. An instrument to measure the proposed competencies would also be valuable in the selection and evaluation processes of leader-managers within SOEs in China.

\section{Conclusion}

The purpose of this HR study was to address a gap in the literature by exploring TM within SOEs in China. By adopting a phenomenological and ethnographical approach, I attempted to describe and understand this phenomenon and to identify strategies for HR professionals to improve TM within SOEs in China. The findings identified 12 themes related to leadership-management selection, development, and practices in China. Utilizing a grounded theory approach, the findings yielded a framework for a proposed TM model for SOEs in China. A TM model can guide HR professionals in understanding and identifying TM strategies within the company including workforce planning, talent acquisition, performance management, development, succession planning, and retention. By developing TM strategies within the company, HR practitioners can work to address the talent gaps in today's state-owned companies in China. 


\section{References}

Abduljlil ALDamoe, F. M., Yazam, M., \& Ahmid, K. B. (2012). The mediating effect of HRM outcomes (employee retention) on the relationship between HRM practices and organizational performance. International Journal of Human Resource Studies, 2(1), 75-88.

Bass, B.M. (1990). Bass \& Stogdill's handbook of leadership: theory, research, and managerial application. New York: Free Press.

Chang, Y.Y. (2005). A study of leadership perceptions of managers in select companies in Taiwan that utilize e-learning. Ph.D. dissertation, University of the Incarnate Word, United States -- Texas. Retrieved September 28, 2011, from ABI/INFORM Global. (Publication No. AAT 3193357).

Chou, S. Y. (2012). Millennials in the workplace: A conceptual analysis of millennials' leadership and followership styles. International Journal of Human Resource Studies, 2(2), 71-83.

Chen, C.C. \& Lee, Y.T. (2008). Leadership and management in China. Cambridge, NY: Cambridge University Press.

Creswell, J. W. (2008). Educational research: Planning, conducting, and evaluating quantitative and qualitative research. Upper Saddle River, NJ: Pearson Prentice Hall.

Dhakhwa, S. \& Enriquez, S. (2008). The relevance of Confucian philosophy to modern concepts of leadership and followership. The Osprey Journal of Ideas and Inquiry. Jacksonville, FL: University of North Florida.

Ford, C.A. (2010). The mind of empire: China's history and modern foreign relations. Lexington, KY: University Press of Kentucky.

Keeley, S. (2004). Leadership development in China: A long way to go. China Staff, 10(5), 12-17.

Kotter, J.P. (2001). What leaders really do. Harvard Business Review. Retrieved July 1, 2012, from http://fs.ncaa.org/Docs/DIII/What\%20Leaders\%20Really\%20Do.pdf.

Kotterman, J. (2006). Leadership versus management: What's the difference? The Journal for Quality and Participation, 29(2), 13-17.

Liang, X., Marler, J.H., \& Cui, Zhiyu (2012). Strategic human resource management in China: East meets West. Academy of Management Perspectives, 26(2), 55-70.

Li, C. (2001). China's leaders: The new generation. Lanham, MD: Rowman \& Littlefield Publishers.

Mathis, R. L. \& Jackson, J. H. (2008). Human resource management. Mason, OH: Thomson South Western.

Northouse, P.G. (2007). Leadership: Theory and practice. (3rd ed.). Thousand Oaks, London: Sage Publications, Inc.

Northouse, P.G. (2010). Leadership: Theory and practice (5th ed.). Thousand Oaks, CA: Sage Publications, Inc.

Stahl, G., Björkman, I., Farndale, E., Morris, S. S., Paauwe, J., \& Stiles, P. (2012). Six principles of effective global TM. MIT Sloan Management Review, 53(2), 25-32. 


\section{Macrothink}

International Journal of Human Resource Studies

ISSN 2162-3058

2014, Vol. 4, No. 3

Vogel, E.F. (2011). Deng Xiaoping and the transformation of China. Cambridge, MA: Belknap of Harvard UP.

Wood, E., Whiteley, A., \& Zhang, S. (2002). The cross model of guanxi usage in Chinese leadership. The Journal of Management Development, 21(3), 263-271.

Yukl, G. (1989). Managerial leadership: A review of theory and research. Journal of Management, 15(2), 251-251.

\section{Acknowledgements}

Thank you to Dr. Jeffrey Walls and Dr. Kenneth Rauch from Indiana Institute of Technology (Indiana Tech) and Dr. Joseph Armstrong from Ball State University for their encouragement and support of this research project.

\section{Copyright Disclaimer}

Copyright for this article is retained by the author(s), with first publication rights granted to the journal.

This is an open-access article distributed under the terms and conditions of the Creative Commons Attribution license (http://creativecommons.org/licenses/by/3.0/). 